\title{
Making the change - how did we succeed? Case Innopeda
}

\author{
Liisa Kairisto-Mertanen', Marjut Putkinen², \\ ${ }^{1}$ Technology and business, Turku University of Applied Sciences, Finland ${ }^{2}$ Health care $m$ \\ Turku University of Applied Sciences, Turku, Finland
}

\begin{abstract}
During the 250 years the world has changed remarkably but in the universities we still tend to apply practices stemming from the middle ages when the first universities were established. Not only providing workforce but also having an impact on the world of work in its region is one of the important tasks of the university. Alongside with the changing working life also the requirements set for graduates have changed. This means that the ways of carrying out education must be adapted according to the changes.

In this paper we describe one change process which has impacted the work done in the specific university and the competences the graduates are reaching. The paper is based on a research done among all the members of one university which had a clear focus and vision about the changes needed.
\end{abstract}

Keywords: Making a change; education; Innopeda. 


\section{Introduction}

The changing working life is often mentioned to form the biggest challenge for many nations. Already more than 30 years ago the concern for the ability of organizations to respond to environmental change was according to Kotter and Schlesinger (2008) mentioned as the most significant management issue and problem to be foreseen during the coming years. This is no wonder as during the last 250 years the society has experienced four industrial revolutions due to which the way how we work, what are the occupations and our lifestyle in general have changed remarkably. However education and the way how we teach have changed relatively less than the society in general.

The first universities were grounded in the middle ages in France and Italy and since those times many practices have remained the same when it comes to carrying out educational tasks. The change in the environment of any educational institution is enormous concerning the problems we are facing today or considering all the equipment awailable to help in the process of learning and teaching. Information is freely and easily accessible to everybody, the teacher is not any longer the only source of information for the students. The society surrounding any educational institution is facing great challenges due to f.ex. the sustainability crisis or aging population. New solutions are needed when tackling these

\section{Managing the change in an educational institution}

\subsection{The change process}

Litterature speaks about first order and second order change. First order change concerns minor adjustments and improvements in one or several dimensions of the organization. It does not change the organizations core. Second order change is transformational and concerns the underlying values, mission and structure of the organization. (Kezar 2001.)

Monitoring the change in the environment and corresponding to it by acting as a local influencer belongs to the tasks of universities of applied sciences in Finland. This change process is adaptative meaning that the changes in the external environment modify and alter the organization when it is making the necessary adptations to follow the development in the external environment. (Kezar 2001.) Managing the task calls for tight relationship with local enterprices and other organizations as well as intensive cooperation in the fields of education, research and development. It is also a prerequisite for developing the internal processes of the university and contributes to its ability to educate students who sto the needs of the changing society. 


\subsection{Managing the change}

Popovic and Plank (2016) present a three stage model for change management. Referring to Kotter's (1996) eight-stage process model of creating change they say that in the context of academic development a successful change management process includes the stages of creating a climate for change, engaging and enabling the organization and implementing and maintaining change.

A successful change management is most likely to succeed when there is a clearly defined aim and a desired end for it. For the change to take place a suitable climate for change should first be created in the organization. All the actions should be directed towards engaging and enabling the organization and finally measures are needed for sustaining and maintaining the change. (Kotter 1996.)

Creating a suitable climate for change in an educational institution is very much about making the needs of the surrounding society clear and visible. Being aware of the changing environment outside of the university should naturally form part of any faculty members life but painting a real life picture about the environment helps in initiating the change process. Understanding why the change must take place is an important beginning part of the change analysis and conversation (Kezar 2001).

Once the need for change is understood the next task is to engage and enable the organization. It is essential to communicate the vision and find the right people from the organization to start the change process with. Senge (1992) speaks about learning organizations and states that in the circumstances of constant change it is necessary that the whole organization is updating its competences all the time. Organization that are competent learners are called learning organizations. Senge (1992) stresses the importance of the members of an organization sharing the same vision of the organization's aspirations and future. It becomes important to have the vision embedded in the organization to ensure a continuos cycle of improvement (Popovic \& Plank 2016.)

The third phase of change management includes implementing and sustaining the change. Using Senge's terminology the organizational members should achieve a situation of personal mastery and have the capacity to produce desirable results. Working with existing mental models, which are deeply ingrained assumptions or generaliszations that individuals hold about the world, also becomes necessary. (Senge 1992.)It is very much possible that people with different mental models understand the same thing differently. This stresses the importance of being aware of of the existing mental models and to know how to influence them to the desired direction. Knowledge generation in both individual and organizational level results from the interaction of acquired information with existing mental models. The actions taken are ultimately based on decisions made about the cause of a problem and the perceived outcomes of any actions we take to correct the problem. (Senge 1992) 


\subsection{Case Innopeda}

The need for innovations is recognized everywhere in the society. Already ten years ago the working life expressed a need to get graduates who have cross-disciplinary competence.

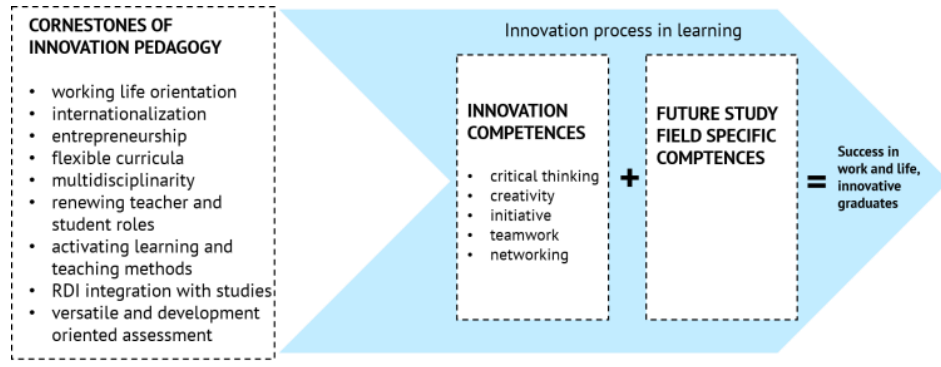

Figure 1. Innovation pedagogy in a nutshell

Innovation pedagogy can be presented according to figure 1 . The aim of the educational process is to create success in work and life for the students but also for the university and for the whole society surrounding the university. The aims are reached when the innovation process in learning creates both study field specific competences as well as innovation comptences. The definition of Innovation competences - creativity, initiative, critical thinking, teamwork and networking - is based on the results of international research projects. (Kairisto-Mertanen\& all. 2011; Marin-Garcia \& all. 2013; 2016). The conrnestones must be found in the learning learning environment to quarentee the presense of Innopeda.

\section{Purpose of the paper and methods used}

The purpose of this paper is to reflect the change process at TUAS by presenting the views of university personnel about innovation pedagogy and how it is shown in everyday practice of the university. The data was collected using a Webrobol questionnaire which was electronically mailed to the whole personnel of TUAS. The questionnaire consisted of 5 open questions aimed at exploring the attitude towards innovation pedagogy and how it is shown in the everyday work of the respondents.

Because of the organizational change taking place at the same time at TUAS the researchers did not get the permission to personally collect the answers or motivate the respondents. This had to be left to the new management. All this resulted in altogether 148 returned questionnaires representing a response reate of $20 \% .116$ of the responses came from teaching staff, est of the responses stemming from other personnel groups. The responses were analyzed in one gategory using the Webrobol tools. Using subcategories was not possible due to the small amount of responsses. Innovation pedagogy represents the organizational culture of TUAS which supports keeping also the nonteaching staff members in the analysis. 


\section{The change process at TUAS}

Innovation pedagogy was mentioned for the first time around year 2008 at the sme time Finland's innovation strategy was launced year 2008 and it put great responsibility to the universities of applied sciences in creating innovations. It took some years until Innovation pedagogy was officially included in the strategy of the university indicating that it shoud form the educational approach followed by every member of the organization. During the path many obstacles were met and neither faculty members, other staff nor students were eager to accept the new approach without questioning. However the organizational structures at TUAS support implementing a multidisciplinary approach in learning and teaching. The cross-disciplinary educational units make it possible for the students to meet students from many different degree programs.

The change from teacher centric way of operation to student centered culture is a must when aiming at producing innovation competences. Making the change happen has required developing the management of the university and finding new forms of cooperation between faculty and students. It has also been necessary to motivate the faculty to continuous learning and rethinking of their present ways of delivering education. (Kettunen \& all. 2013; Konst \& Kairisto-Mertanen, 2018).

All the phases of the change process presented by Popovic and Plank (2016) can be found in the process we have undergone at TUAS. It has proven to be extremely important to first create a climate for change by presenting reliable proof about the necessity. During that phase we made many mistakes as we took it for granted that the need for change is understood if enough proof is presented.

Engaging and enabling the organization was done by organizing numerous events where people were provided a chance to get to know each other as there can be no cooperation without knowing the people to cooperate with. During these events we shared knowledge about good practices and developed new ideas together. In the beginning people had many prejudices but along the years trust was gradually born. An important step in imbedding innovation pedagogy in the everyday work at the university was the development of an internal training program meant for every member of the staff.

An important step in maintaining the change was that innovation pedagogy was the implementation of innovation pedagogy in the strategy of the university. At the moment it is considered as a concept which all the personnel at TUAS is developing together. 


\section{How did we succeed}

\subsection{The Cornestones of innovation pedaogy in practice}

The cornerstones of innovation pedagogy are essential tools when putting it into practice. For innovation competences to born the learning environments is essential. Those students who have studied more according to the environments defined in the cornerstones have developed their innovation competences more than other students. The methods used in lerning, flexible study plan, internationalization, multidisciplinarity and workinglife orientation seem to be especially important. (Keinänen \& Kairisto-Mertanen, 2019.)

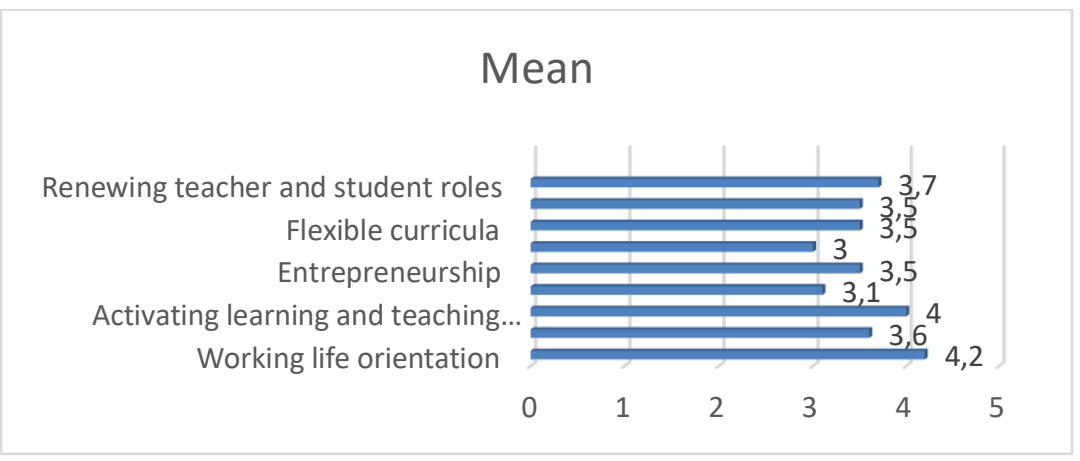

Figure 2. The conrnerstones in everyday work

As can be seen from figure 2 the university personnel reports applying the cornerstones quite well in their everyday work. Biggest means are for working life orientation and for activating learning and teaching methods. The smallest means are for entrepreneurship and RDI integration with studies. Based on these results it can be concluded that working life oriented and activating learning and teaching methods are in wide use at TUAS.

The responses also show that the learning environments at TUAS are reported as multidisciplinary and international. The assessment methods are reported as versatile and the student and teaching roles are renewing. Entrepreneurships and RDI integration with studies are reported as least applied cornerstones. This might be due to the fact that implementing them is more difficult than implementing other cornerstones.

\subsection{Understanding of Innovation pedagogy at TUAS}

The research also aimed at forming a picture about how TUAS personnel understand Innovation pedagoy. The obtained 147 responses were analyzed with the textmining tool in Webrobol software.

Examining the words in the responses shows a connection between the students and the working life and cooperation between both. Very often the discourse among teachers moves 
around teaching although learning is the concept whe really should be interested in. Teaching describes the work of a teacer but learning is the process of the student and it must happen at all levels of education. The research shows that learning is put at the center concerning ideas about innovation pedagogy.

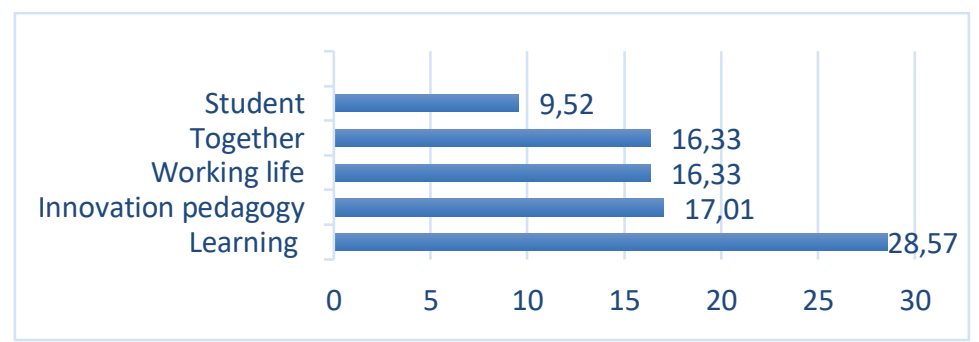

Figure 3. The most common words connected to innovation pedagogy

As table 3 presents he most common words in the responses were in addition to the word "innovation pedagogy" the words "working life", "learning", "together"and "student". These answers can be interpreted to reflect understanding aobut student centered learning which happens together with working life. Learning in its different forms is represented in $30 \%$ of the answers . Words "working life" and "together" which can be interpreted to represent cooperation with working life are represented in $30 \%$ of the responses.

In the open ended questions the respondents provided several good definitions of innovation pedagogy, f.ex. "Developing student's (and mine as a teacher) innovation competences starting from the needs of the working life by using student centered learning methods".

\subsection{Innovation pedagogy at the everyday work of the university}

The respondents were also presented a question concerning how innovations pedagogy is shown in his/her everyday work. The 146 responses reflect the most common words associated with the teacher everyday work. According to figure The most common word is "student" in its different forms, 34,6\% of the responses, which reflects the central of the student in Innovation pedaogy. The next common word are "teachning, 10,3\%", "practice, 9,6\%", "different, 9,6\%" and "more 8,9\%".

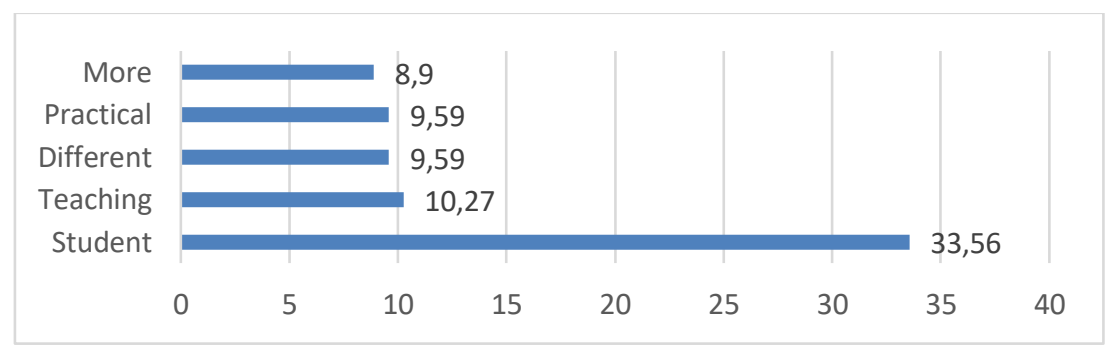


Figure 4. The most common words reflecting teacher's everyday work

The word charts reflect student work by connecting words "learning", "practice", "projects" and "more" closely together. This can be interpreted to reflect that innovation pedagogy is a widely accepted approach in the everyday work of the university.

\section{Conclusion}

Making the change in educational institution has not been an easy process. It has required several years to actually make the change but according to the results of the research made among the personnel of the university we are following the right track at TUAS.

Universties are facing many challenges at the moment; at the same time they should be able to keep their competing position, develop their learning methods, create high quality scientific research and reduce costs. New approaches to university pedagogy are urgently needed. This example from Turku University of Applied Sciences provides one approach to tackle the challenges. It shows that a change is not very rapid but it is possible and achievable when the right measures are found.

\section{References}

Popovic, C. \& Plank, K. (2016) Managing and Leading change. Models and Practices in Baume, D. \& Popovic, C. (2016) Advancing Practice in Academic Development. Routledge.

Kotter, J. P. (2012) Leading Change. Harward Business Review Press. USA.

J. P. Kotter \& L. A. Schlesinger (2008) Choosing strategies for change. Harward Business Review, July - August, https://hbr.org/2008/07/choosing-strategies-for-change

Kezar A. (2001) Understanding and Facilitating Organizational Change in the 21st Century. ASHE-ERIC Higher Educational Report, Vol. 28, 4. San Francisco, Kalifornia.

Senge, P. M. (1992) The Fifth Discipline: The Art \& Practice of the Learning Organization. Random House Australia: Milson Point, NSW.

Kettunen, J., Kairisto-Mertanen, L., \& Penttilä, T. (2013). Innovation pedagogy and desired learning outcomes in higher education. On the Horizon, 21(4), 333-342.

Keinänen M., Kairisto-Mertanen L, (2019) "Researching learning environments and students' innovation competences", Education + Training, Vol. 61 Issue: 1, pp.17-30, https://doi.org/10.1108/ET-03-2018-0064

Konst, T., \& Kairisto-Mertanen, L. (2018). Innovation Pedagogy: preparing Higher Education Institutions for Future Challenges. Course Material from Turku University of applied sciences 115. Tampere: Suomen Yliopistopaino, Juvenes Print Oy.

Marin-Garcia, J., Pérez-Peñalver, J., \& Watts, F. (2013). How to assess innovation competence in services: The case of university students. Direccion y Organization, 50, 48-62. 